\title{
The RAISE Health initiative for workers, companies, and
} communities

The Evidence Project

Follow this and additional works at: https://knowledgecommons.popcouncil.org/departments_sbsr-rh

Part of the Demography, Population, and Ecology Commons, Family, Life Course, and Society Commons, International Public Health Commons, and the Work, Economy and Organizations Commons How does access to this work benefit you? Let us know!

\section{Recommended Citation}

"The RAISE Health initiative for workers, companies, and communities," Activity brief. Washington, DC: The Evidence Project, 2015. 


\section{THE RAISE HEALTH INITIATIVE EOR WORKERS, COMPANIES, AND COMMUNITIES}

Resources and Action on International Standards and Engagement

\section{ACTIVITY BRIEF}

RAISE Health is an initiative to improve the health of women and men factory and farm workers in developing countries through changes in global and corporate policies and workplace practices. Effective management of workplace health is good for companies and workers alike, resulting in better health and morale, better labor-management relations, empowerment of women, and better use of company health investments. Worker health is typically one of the most neglected areas in business operations.
Our goal is to utilize the existing business systems of corporations and their supplier farms and factories to address the health needs of millions of women and men workers in such overlooked areas as family planning, reproductive health, maternal and child health, nutrition, hygiene, and other important health concerns.

RAISE Health promotes worker health by:

(1) Developing and advocating for better policies within the global framework of standards, codes, and compliance for corporations and their supply chains. This framework is influenced by a range of international and government actors in corporate social responsibility, human rights, certification processes for fair trade, labor rights, and the environment.

(2) Documenting and disseminating best practices. This includes addressing policies, standards, and legal requirements of multinational corporations as well as the management functions relating to worker health.

\section{OUR APPROACH}

RAISE Health is a major activity of the USAID-funded Evidence Project. Implemented by Meridian Group International, Inc., an Evidence Project partner, RAISE Health combines implementation science with its extensive experience implementing workplace health programs and promoting better policies and practices within the global framework of codes and compliance.

We collaborate with companies, public health groups, and civil society organizations to identify systemic incentives for corporations and their supplier farms and factories to engage more effectively in the health of their workers. Business has much to gain from a greater focus on worker health, particularly for women workers, in terms of productivity, workforce development, and returns on existing investments in health services and programs.

\section{(1) USAID Evidence}




\section{OUR ACTIVITIES}

Worker health has traditionally been limited to the important but narrow area of occupational health and safety. We focus on a broader range of health needs of workers and the communities in which companies operate, giving greater visibility to the human rights and business reasons for investing in health services and education for workers. Our activities include:

PROMOTING AN ENABLING ENVIRONMENT AT THE GLOBAL AND LOCAL LEVELS. RAISE Health is part of a five-year USAID project to improve the health of female garment workers in Cambodia. It is facilitating policy changes at the factory, corporate, and government levels to create an environment that increases access to family planning and reproductive health services. The project builds on RAISE Health's global efforts to promote strong health policies for companies and their supply chains. Working with Business for Social Responsibility (BSR), RAISE Health has developed voluntary Workplace Health Facility Standards and Management Benchmarks that adapt best public health practices to the commercial workplace.

RE-ENGINEERING WORKPLACE HEALTH FACILITIES. With funding from the HRA Pharma Foundation, RAISE Health has pilot-tested a re-engineered health service in a Haitian factory, building the factory's human resource capacity to manage its health staff and infirmary, instituting clinical best practices in the health clinic, and developing a proactive, preventive role for nurses, including promotion of family planning. We are utilizing these findings in providing technical assistance to Levi Strauss \& Co. and to HERproject to replicate components of the model at a supplier factory in Egypt and elsewhere.

TRAINING WORKPLACE MANAGERS AND AUDITORS. RAISE Health is partnering with the Worldwide Responsible Accredited Production (WRAP), an NGO that certifies workplaces on compliance with social standards, to develop a training for company leaders on best management in women's health.

INCREASING ACCESS TO HEALTH EDUCATION MATERIALS AT THE WORKPLACE. Bayer Pharmaceuticals and RAISE Health are adapting existing family planning and reproductive health materials targeted to workers that can be accessed online and printed onsite by workplace health staff or management. Bayer and RAISE Health will be collaborating with other organizations to expand the package of health materials. This activity is also linked to promoting policies that expand worker access to health services and information.

CONDUCTING IMPLEMENTATION RESEARCH TO IMPROVE WORKER HEALTH. The Evidence Project is undertaking implementation research in Cambodia's garment sector on approaches to meeting female workers' needs for family planning and reproductive health information and services. It is also evaluating BSR's HERproject model of workplace health education in Bangladesh to assess changes in female garment workers' knowledge across a variety of health domains and their use of products and services from on-site clinics. Evidence generated from these projects will inform policy changes and best practices for local and international scale-up.

\section{OUR PARTNERSHIPS}

Bayer HealthCare Pharmaceuticals

The Better Work Programme of the International Labor

Organization (ILO) and the International Finance

Corporation (IFC)

Business for Social Responsibility/HERproject

Caribbean Island Apparel

HRA Pharma Foundation
Levi Strauss \& Co. and its Improving Worker

Well-Being Program

Marie Stopes International/Cambodia

Worldwide Responsible Accredited Production (WRAP)

Verité
The Evidence Project is led by the Population Council in partnership with INDEPTH Network, International Planned Parenthood Federation, Management Sciences for Health, PATH, Population Reference Bureau, and a University Research Network. Other partners are FHI360, Meridian Group International, Inc., and What Works Association.
The Evidence Project is made possible by the generous support of the American people through the United States Agency for Internationa Development (USAID) under the terms of cooperative agreement no. AID-OAA-A-13-00087. The contents of this document are the sole responsibility of the Evidence Project and Population Council and do not necessarily reflect the views of USAID or the United States Government.

For more information, go to www.meridian-group.com or evidenceproject.popcouncil.org or contact Carolyn Rodehau at c.rodehau@meridian-group.com 